\title{
Humanwissenschaftliche Fakultät
}

Heinz Völler | Annett Salzwedel | Aischa Nitardy | Hermann Buhlert | András Treszl | Karl Wegscheider

\section{Effect of cardiac rehabilitation on functional and emotional status in patients after transcatheter aortic-valve implantation}

Suggested citation referring to the original publication:

European Journal of Preventive Cardiology 22 (2015) 5, p. 568-574

DOI http://dx.doi.org/10.1177/2047487314526072

ISSN (print) 2047-4873

ISSN (online) 2047-4881

Postprint archived at the Institutional Repository of the Potsdam University in:

Postprints der Universität Potsdam

Humanwissenschaftliche Reihe ; 385

ISSN 1866-8364

http://nbn-resolving.de/urn:nbn:de:kobv:517-opus4-404100 

Effect of cardiac rehabilitation on functional and emotional status in patients after transcatheter aortic-valve implantation
20I5, Vol. 22(5) 568-574

(C) The European Society of Cardiology 2014

Reprints and permissions: sagepub.co.uk/journalsPermissions.nav DOI: I0.II77/20474873|4526072 ejpc.sagepub.com

(S)AGE

\author{
Heinz Völler ${ }^{1,2}$, Annett Salzwedel', Aischa Nitardy², \\ Hermann Buhlert ${ }^{2}$, András Treszl ${ }^{3}$ and Karl Wegscheider ${ }^{3}$
}

\begin{abstract}
Background: Transcatheter aortic-valve implantation (TAVI) is an established alternative therapy in patients with severe aortic stenosis and a high surgical risk. Despite a rapid growth in its use, very few data exist about the efficacy of cardiac rehabilitation (CR) in these patients. We assessed the hypothesis that patients after TAVI benefit from CR, compared to patients after surgical aortic-valve replacement (sAVR).

Methods: From September 2009 to August 20II, 442 consecutive patients after TAVI $(n=76)$ or sAVR $(n=366)$ were referred to a 3-week CR. Data regarding patient characteristics as well as changes of functional (6-min walk test. 6-MWT), bicycle exercise test), and emotional status (Hospital Anxiety and Depression Scale) were retrospectively evaluated and compared between groups after propensity score adjustment.

Results: Patients after TAVI were significantly older $(p<0.00 \mathrm{I})$, more female $(p<0.00 \mathrm{I})$, and had more often coronary artery disease $(p=0.027)$, renal failure $(p=0.012)$ and a pacemaker $(p=0.032)$. During CR, distance in 6-MWT (both groups $p \leq 0.00 \mathrm{I}$ ) and exercise capacity (sAVR $p \leq 0.00 \mathrm{I}$, TAVI $p \leq 0.05$ ) significantly increased in both groups. Only patients after sAVR demonstrated a significant reduction in anxiety and depression $(p \leq 0.00 \mathrm{I})$. After propensity scores adjustment, changes were not significantly different between sAVR and TAVI, with the exception of 6-MWT $(p=0.004)$. Conclusions: Patients after TAVI benefit from cardiac rehabilitation despite their older age and comorbidities. CR is a helpful tool to maintain independency for daily life activities and participation in socio-cultural life.
\end{abstract}

\title{
Keywords
}

Cardiac rehabilitation, emotional status, functional capacity, surgical aortic valve replacement (sAVR), transcatheter aortic valve implantation (TAVI)

Received 20 November 2013; accepted 8 February 2014

\section{Introduction}

Aortic stenosis is a common valve disease in elderly patients, associated with a high risk of death, when untreated. ${ }^{1}$ Surgical aortic valve replacement (sAVR) improves prognosis in patients with low surgical risk. ${ }^{2}$ But many elderly patients with comorbidities are not appropriate candidates for $\mathrm{sAVR}^{3}$ Transcatheter aortic-valve implantation (TAVI) is an alternative option in these high-risk patients ${ }^{4-9}$ and is now routinely available for many patients.

In the PARTNER study, TAVI was superior to standard medical therapy in patients with severe aortic stenosis, who were not suitable for surgery. ${ }^{5}$
It reduces rates of death and hospitalization, ${ }^{6,7}$ improves significantly health-related quality of life, ${ }^{10}$ and is associated with an increase in functional status, ${ }^{11-13}$ even in patients aged $\geq 80$ years. ${ }^{14}$ According to the German Aortic Valve Registry,

\footnotetext{
'University of Potsdam, Potsdam, Germany

${ }^{2}$ Rehabilitation Centre for Cardiovascular Diseases, Rüdersdorf, Germany

${ }^{3}$ University Medical Centre, Hamburg-Eppendorf, Germany
}

\section{Corresponding author:}

Heinz Völler, Centre of Rehabilitation Research, University of Potsdam, Am Neuen Palais 10, D-I4469 Potsdam, Germany.

Email: heinz.voeller@uni-potsdam.de 
there has been a rapid growth in its use, accounting for $38.5 \%$ of patients who underwent an aortic valve replacement in 2011. ${ }^{15}$

Cardiac rehabilitation (CR) and physical activity are recommended treatments after cardiac valve surgery, ${ }^{16-18}$ which positively improves morbidity, exercise capacity, and quality of life. ${ }^{19,20}$ Despite an increasing number of patients undergoing TAVI, there are very few data available about the efficacy of CR in these often multimorbid patients.

Therefore, the aim of this study was to evaluate the effect of CR on functional and emotional parameters in patients after TAVI in comparison to patients after sAVR in a propensity score-adjusted model.

\section{Methods}

\section{Patients}

From September 2009 to August 2011, 442 consecutive patients $(69.94 \pm 11.08$ years; $61.3 \%$ men) after aorticvalve replacement due to severe aortic stenosis were referred for a 3-week inpatient CR to the Klinik am See, Germany, a rehabilitation centre for cardiovascular diseases. The patients had undergone a transcatheter approach (n=76: 42 transfemoral and 33 transapical) or a surgical aortic-valve replacement $(n=366)$ in four different heart centres. In Germany all eligible patients after aortic valve replacement are offered a cardiac rehabilitation after discharge from hospital.

\section{Data collection}

Sociodemographic data, medical history, and clinical status of the admitted patients as well as all results of medical investigations, done in the rehabilitation centre, are recorded and stored in an electronic database. The stored data regarding patient characteristics as well as functional and emotional status of these patients were extracted and evaluated for this study retrospectively.

\section{Rehabilitation programme}

All patients underwent a structured rehabilitation programme, including individualized physical training, education, and psychological support. ${ }^{18}$ Additional treatment during the rehabilitation stay was done depending on its necessity. Aerobic exercise consisted of training on a bicycle ergometer in different workload classes, depending on the initial exercise intensity, outdoor walking, gymnastics in groups or single, and resistance training of the lower extremities. All sessions were controlled by approved physical therapists and were performed each four or five times per week. Additionally, patients received an individual psychological support. The number of sessions depended on the need and wish of the patients. Psychological education also included stress management, Tai Chi, and progressive muscle relaxation.

\section{Functional evaluation}

The functional evaluation of the study patients comprised a 6-min walk test (6-MWT) and a cycle-exercise test, which are performed in all cardiac patients at admission and at discharge from CR.

Standardized 6-MWT was performed with a distance-measuring device (Nestle Rolltachometer, Dornstetten, Germany). To evaluate the maximal exercise capacity, patients performed an individualized symptom-limited cycle test on a cycle ergometer (Cardiovit CS-200; Schiller, Germany) up to the submaximal predicted heart rate $(85 \%$ of age-adjusted maximum heart rate). Under the supervision of a physician, the stress-test protocol started with $25 \mathrm{~W}$ followed by $25 \mathrm{~W}$ increase every 2 min until exhaustion. During the exercise test, a 3-lead ECG was recorded continuously to detect ischaemia or arrhythmias. Additionally, blood pressure was controlled every 2 min. The test was stopped, when the standard criteria for termination were reached.

Prior to the exercise test, all patients received a 12lead ECG and underwent a two-dimensional echocardiography to evaluate left ventricular function and valve haemodynamics using a $3 \mathrm{~S}$ probe of Vivid 7 (GE Ving Med, Horten, Norway).

\section{Emotional evaluation}

The emotional status was evaluated using the validated German version of the standardized Hospital Anxiety and Depression Scale (HADS) at the beginning and end of $\mathrm{CR}^{21,22}$ Patients with a HADS score $\geq 11$ were offered an individual psychological support.

\section{Statistical analysis}

Qualitative (discrete) variables are reported as count and percentage, continuous variables as mean \pm standard deviation. Baseline comparisons between groups were performed using chi-squared tests for discrete and t-tests for continuous variables. For better comparability, changes were expressed in percentage from baseline and analysed based on differences of log-transformed measurements. Changes within groups were tested using paired-sample t-tests for continuous variables. Since this was an observational study and 
patients were not randomized to treatment groups, we aimed to control for selection bias when evaluating the effect of treatment. Thus, following a backward variable selection procedure propensity scores (i.e. probability of a patient being assigned into the TAVI treatment group) were calculated based on the baseline variables and multivariable analyses were adjusted for this score. $p$-values $\leq 0.05$ were considered significant. Statistical analyses were calculated using SAS 9.2 (Cary, NC, USA).

\section{Results}

\section{Patient characteristics}

Patients after TAVI were significantly older and more female than patients after sAVR $(80.30 \pm 6.15$ vs. $67.78 \pm 10.66$ years and 57.9 vs. $33.7 \% ; p<0.001$, respectively). They revealed more often a coronary heart disease ( 64.5 vs. $50.5 \% ; p=0.027)$ or markedly renal failure with a glomerular filtration rate $<60 \mathrm{ml} /$ $\min (42.7$ vs. $31.7 \% ; p=0.067)$, underwent more often a pacemaker implantation (15.8 vs. $7.9 \% ; p=0.032)$, and had a higher NYHA stage $\left(p_{\text {trend }}=0.003\right)$. Other comorbidities, such as chronic obstructive pulmonary disease (COPD), diabetes mellitus, and atrial fibrillation, were not significantly different between the two groups (Table 1).

The patients revealed no significantly different length of hospital stay (TAVI $15.55 \pm 15.38$ vs. sAVR $17.3 \pm 11.28$ days) or time frame from the index procedure to admission to the rehabilitation centre (TAVI $24.05 \pm 15.82$ vs. sAVR $26.91 \pm 18.71$ days). The mean stay in the rehabilitation centre was $20.33 \pm 4.03$ days with a significantly shorter duration in patients after TAVI (TAVI $19.17 \pm 4.54$ vs. SAVR $20.58 \pm 3.88$ days; $p=0.013$ ). Patients after TAVI spent more time in the intermediate care unit, needed more monitoring support (due to paroxysmal atrial fibrillation or volume balance in patients with renal failure) compared to the patients after sAVR (sAVR $3.74 \pm 4.21$ vs. TAVI $5.29 \pm 4.21$ days; $p=0.216$ ). But all patients could complete the CR without a severe complication.

\section{Functional and emotional status at the beginning of cardiac rehabilitation}

Patients after sAVR achieved a significantly longer mean distance in the 6-MWT (sAVR $300.74 \pm 102.36$ vs. TAVI $262.45 \pm 90.44 \mathrm{~m} ; p=0.010)$ and a higher maximal exercise capacity compared to patients after TAVI (sAVR $69.15 \pm 26.63$ vs. TAVI

Table I. Patient characteristics at admission to $C R$

\begin{tabular}{|c|c|c|c|c|c|c|}
\hline \multirow[b]{2}{*}{ Characteristic } & \multirow[b]{2}{*}{$\begin{array}{l}\text { sAVR } \\
(n=366)\end{array}$} & \multicolumn{3}{|l|}{ TAVI } & \multirow[b]{2}{*}{$\begin{array}{l}\text { Total } \\
(n=442)\end{array}$} & \multirow[b]{2}{*}{$p$-value } \\
\hline & & $\begin{array}{l}\text { Total } \\
(n=76)\end{array}$ & $\begin{array}{l}\text { Transfemoral } \\
(n=42)\end{array}$ & $\begin{array}{l}\text { Transapical } \\
(n=33)\end{array}$ & & \\
\hline Gender (male, $n$ ) & $239(66.3)$ & $32(42.1)$ & $18(42.9)$ & $13(39.4)$ & $27 \mid(6 \mid .3)$ & $<0.00 \mathrm{I}$ \\
\hline Age (years) & $67.78 \pm 10.66$ & $80.30 \pm 6.15$ & $80.29(6.21)$ & $80.30(6.27)$ & $69.94 \pm 11.08$ & $<0.001$ \\
\hline BMI $\left(\mathrm{kg} / \mathrm{m}^{2}\right)$ & $27.21 \pm 4.68$ & $26.10 \pm 4.44$ & $26.20(4.7 I)$ & $25.97(4.22)$ & $27.02 \pm 4.66$ & 0.0591 \\
\hline Stay in CR (days) & $20.58 \pm 3.88$ & $19.17 \pm 4.54$ & $19.43(4.35)$ & I8.79 (4.87) & $20.33 \pm 4.03$ & 0.013 \\
\hline COPD & $45(12.3)$ & II (I4.5) & $6(14.3)$ & $5(15.2)$ & $56(12.7)$ & 0.603 \\
\hline Diabetes mellitus & $98(26.8)$ & $27(35.5)$ & $14(33.3)$ & $12(36.4)$ & $125(28.3)$ & 0.123 \\
\hline CHD & $185(50.5)$ & $49(64.5)$ & $29(69.1)$ & $19(57.6)$ & $234(52.9)$ & 0.027 \\
\hline GFR (ml/min) & $68.80 \pm 19.15$ & $62.73 \pm 18.21$ & $62: 80(17.63)$ & $62.00(19.14)$ & $67.77 \pm 19.11$ & 0.012 \\
\hline$<60$ & $116(31.7)$ & $32(42.7)$ & $17(40.5)$ & $15(46.9)$ & I 48 (33.6) & 0.067 \\
\hline$<30$ & $12(3.3)$ & $2(2.7)$ & $2(4.8)$ & $0(0)$ & $14(3.2)$ & 0.783 \\
\hline Atrial fibrillation & $58(15.9)$ & $12(15.8)$ & $8(19.1)$ & $4(12.1)$ & $70(15.8)$ & 0.990 \\
\hline Sinus rhythm & $265(72.4)$ & $51(67.1)$ & $28(66.7)$ & $22(66.7)$ & $316(7 \mid .5)$ & 0.352 \\
\hline Pacemaker & $29(7.9)$ & $12(15.8)$ & $9(2 \mid .4)$ & $3(9.1)$ & $41(9.3)$ & 0.032 \\
\hline LVEF (\%) & $56.19 \pm 8.12$ & $57.11 \pm 9.19$ & $57.95(10.20)$ & $56.70(6.95)$ & $56.35 \pm 8.31$ & 0.384 \\
\hline$\leq 40$ & $24(6.6)$ & $4(5.3)$ & $3(7.1)$ & $0(0)$ & $28(6.4)$ & 0.670 \\
\hline NYHA (I/II/III/IV) & $125 / 145 / 94 / 2$ & $14 / 32 / 29 / \mid$ & $10 / 16 / 15 / 1$ & $4 / 16 / 13 / 0$ & $139 / 177 / 123 / 3$ & $0.003 *$ \\
\hline
\end{tabular}

Values are $n(\%)$ or mean \pm standard deviation.; *Cochrane-Armitage trend test.; BMI, body mass index; CHD, coronary heart disease; COPD, chronic obstructive pulmonary disease; CR, cardiac rehabilitation; GFR, glomerular filtration rate; LVEF, left ventricular ejection fraction; sAVR, surgical aorticvalve replacement; TAVI, transcatheter aortic-valve implantation. 
$53.66 \pm 22.65 \mathrm{~W} ; p<0.001)$ at admission of cardiac rehabilitation.

Regarding emotional status, the two study groups showed no significant difference in the anxiety and depression score at baseline (anxiety: sAVR 5.29+/-3.95 vs. TAVI $4.37+/-3.26 ; p=0.157$; depression: sAVR $5.40+/-4.15$ vs. TAVI $5.00+/-3.82 ; p=0.550)$.

\section{Calculation of propensity scores}

For calculation of the propensity scores, a backward variable selection procedure was performed with all baseline variables. Weight at admission and age remained significant in the model and were used to calculate propensity scores.

\section{Effect of cardiac rehabilitation on functional status}

Following CR, the 6-MWT increased in both groups (Figure 1 and Table 2). In the propensity score-adjusted model, the change in the distance walked in the 6-MWT between admission and discharge was significantly lower in the TAVI group compared to sAVR patients (median, range: $-15.89 \%,-5.53$ to $-25.09 \% ; p=0.004)$.

Regarding exercise capacity, both groups profited from CR, showing significant increases (sAVR $26.72 \%, 21.62$ to $32.02 \%$, TAVI $19.84 \%, 4.76$ to $37.08 \% ; p<0.001$ and $p=0.010$, respectively; Figure 2, Table 2). Comparing the two groups in the propensity score-adjusted model, however, there

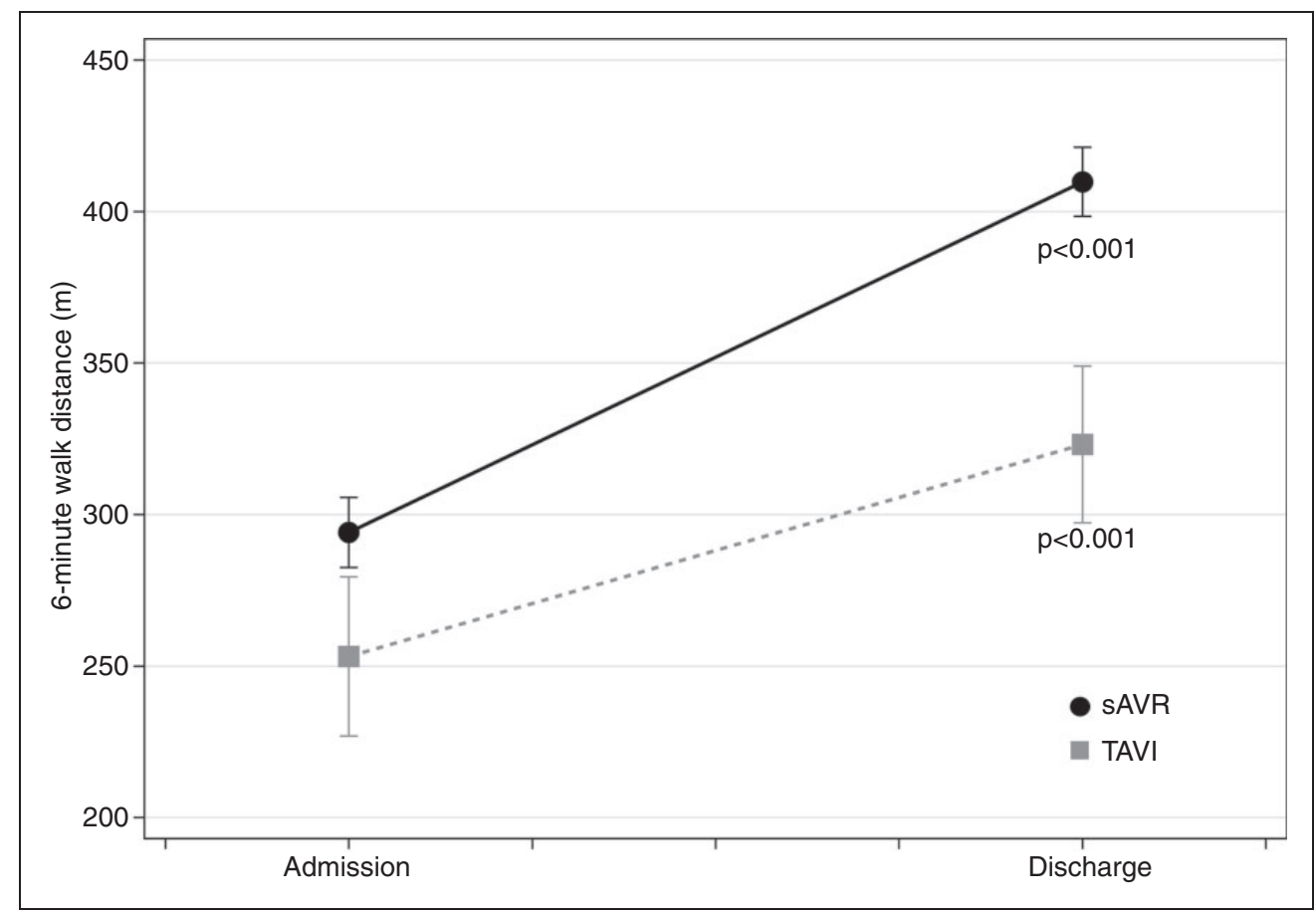

Figure I. Effect of CR on 6-min walk test in patients after TAVI and sAVR.

$\mathrm{CR}$, cardiac rehabilitation; sAVR, surgical aortic valve replacement; TAVI, transcatheter aortic valve implantation.

Table 2. Changes in functional and emotional status from baseline after $C R$ in patients after surgical and transcatheter aortic valve replacement

\begin{tabular}{llllll}
\hline & \multicolumn{2}{l}{ Changes during CR } & & \\
\cline { 2 - 3 } Variable & sAVR & TAVI & Propensity score-adjusted difference & $p$-value \\
\hline 6-MWT & $45.5 \mathrm{I}(38.87 \text { to } 50.38)^{* *}$ & $28.13(20.59 \text { to } 36.15)^{* * *}$ & $-15.89(-5.53$ to -25.09$)$ & 0.004 \\
Exercise capacity & $26.72(21.62 \text { to } 32.02)^{* *}$ & $19.84(4.76 \text { to } 37.08)^{*}$ & $-11.26(-22.24$ to 1.28$)$ & 0.076 \\
Anxiety score & $-23.60(-30.09 \text { to }-16.5 I)^{* * *}$ & $-17.1(-35.45$ to 6.40$)$ & $-6.22(-22.00$ to 44.66$)$ & 0.700 \\
Depression score & $-23.36(-29.11 \text { to }-17.12)^{* * *}$ & $-17.10(-34.61$ to 5.11$)$ & $-0.92(-23.96$ to 29.12$)$ & 0.946 \\
\hline
\end{tabular}

Values are \% from baseline (95\% confidence interval).; $p$-values for improvement measurement: ${ }^{*} p<0.05 ; * * p<0.001$.; 6-MWT, 6-min walk test; CR, cardiac rehabilitation; sAVR, surgical aortic-valve replacement; TAVI, transcatheter aortic-valve implantation. 


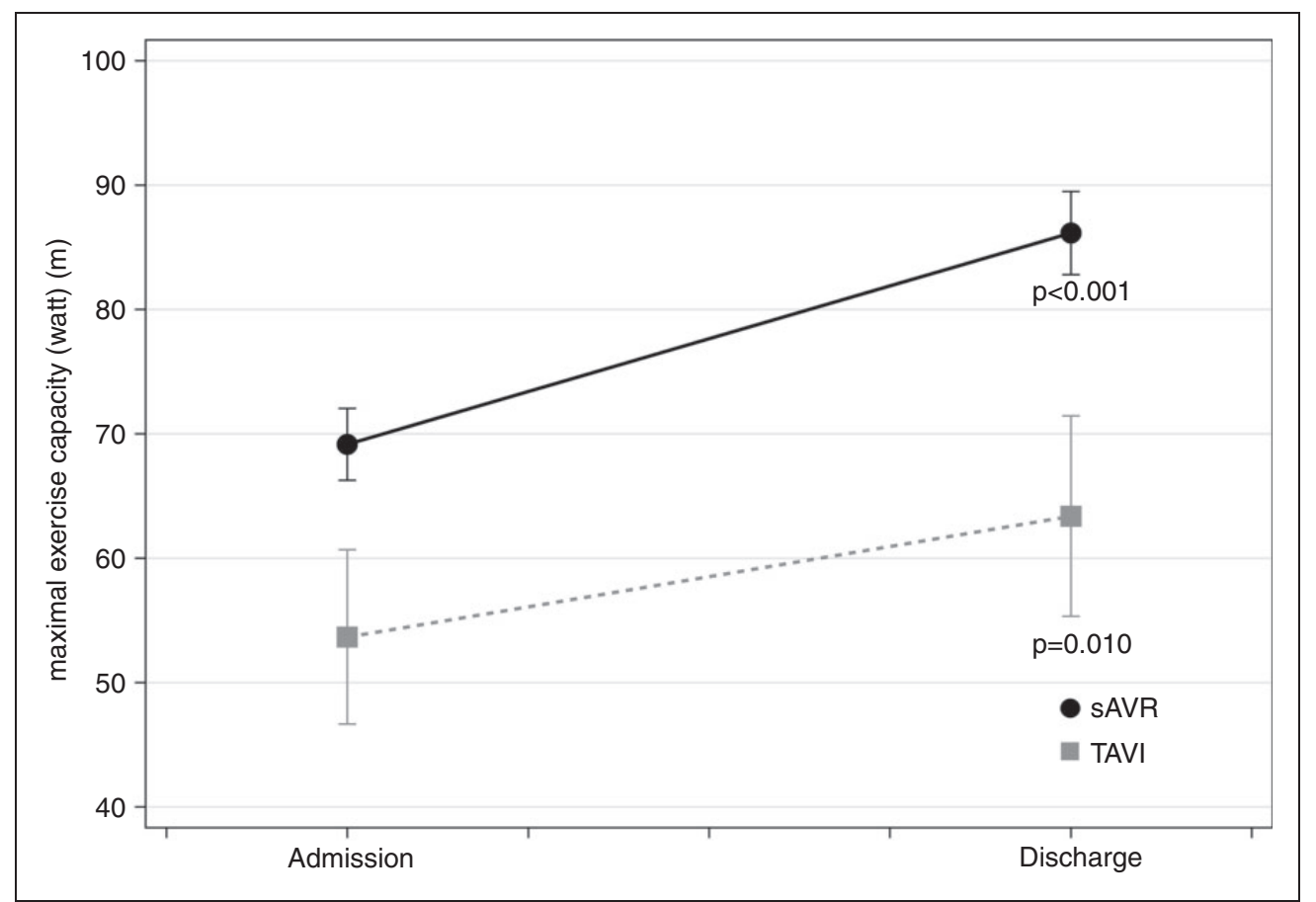

Figure 2. Effect of $C R$ on maximal exercise capacity in $W$ in patients after TAVI and sAVR.

was no significant difference between the two procedures $(p=0.076)$.

\section{Effect of cardiac rehabilitation on emotional status}

The evaluation of depression and anxiety in the two groups using HADS revealed a significant reduction in depression and anxiety at the end of CR after sAVR $(-23.36 \%,-29.11$ to $-17.12 \%$ and $-23.60 \%$, -30.09 to $-16.51 \% ; p<0.001$ for both scores). Patients after TAVI showed no significant difference $(p=0.117$ and 0.134 , respectively). After propensity score adjustment, there was no significant difference in depression symptoms in either group comparing the scores at admission and discharge from CR.

\section{Discussion}

According to the literature available, very few data have reported about the effect of CR on functional and emotional status in patients after TAVI. The main finding of our observational propensity-matched study was that CR was safe, feasible, and improved physical performance significantly, tested using 6-MWT and maximal exercise capacity, in these elderly, often multimorbid patients. These findings correlate with those reported recently in the only existing small observational single-centre study, which also showed that patients after TAVI improved in 6-MWT after $\mathrm{CR}{ }^{23}$

\section{Effect of cardiac rehabilitation on functional status}

In our study, the mean distance in the 6-MWT was significantly improved during $\mathrm{CR}$ in both groups. In the propensity score-adjusted model, the change in the distance walked in the 6-MWT between admission and discharge was significantly lower in the TAVI group compared to sAVR patients.

The 6-MWT was chosen as a functional and an outcome measure test because the test is safe and feasible, even in elderly patients and after cardiac surgery. ${ }^{24-27}$ As a measure of functional capacity, the 6-MWT reflects more the requirements of activities of daily living when compared with other tests. ${ }^{28}$ Patients after TAVI were significantly older, more often female, and had more concomitant diseases than patients after sAVR and therefore showed a significantly shorter mean distance in the 6-MWT at admission. Recent data from the PARTNER trial show that the baseline distance predicts long-term mortality. ${ }^{29}$ Other studies have reported that the distance walked in the 6-MWT is inversely related to age $\mathrm{an}^{30,31}$ and is affected by comorbidities ${ }^{25,32}$ and gender. $^{31}$ Altogether, both groups showed an improvement of more than $50 \mathrm{~m}$, a margin, which was found to be representative for a clinically significant change in functional status in a former study. ${ }^{33}$

At admission to rehabilitation, patients after sAVR showed higher exercise capacity compared to the patients after TAVI. Both groups increased their 
exercise intensity during rehabilitation significantly. However, the direct comparison of the groups after propensity score adjustment revealed a strong but nonsignificant trend in favour of sAVR. Compared to the 6-MWT, the exercise test requires more aerobic performance and this might be the reason for the different results regarding significance in the improvement in the two groups. This could be due to the older age and higher rate of comorbidities in patients after TAVI, which leads to a decline in maximal capacity exercise, but may also result from the different sample sizes of the two groups. In future studies, the functional decline should be assessed on the basis of a composite of variables (e.g. malnutrition, cognition, gait speed, or activities of daily living) to generate the frailty index which is most predictive of functional decline (e.g. prognosis). ${ }^{34}$

\section{Effect of cardiac rehabilitation on emotional status}

HADS was reported to be suitable in assessing symptom severity of anxiety disorders and depression. ${ }^{35}$ In this study, the average levels of depressive and anxiety symptoms according to HADS-Scale at admission were relatively low (Table 2 ) in conformity to usual values in cardiovascular patients.

Only patients after sAVR showed a significant improvement in anxiety symptoms during CR. At admission, patients after sAVR showed a trend of higher level of anxiety compared to patients after TAVI. This may be due to the fact that patients consider surgery as a more life-threatening event than interventional therapy. These patients showed a significant recovery at the end of CR. The provided education and psychological support during rehabilitation could have be a substantial impact on this process. Again, different sample sizes may be an alternative explanation. The direct comparison of the groups did not support the assumption of differences between the groups.

Regarding depressive symptoms, there was an improvement at discharge from CR in both groups, but without significance in the TAVI-Group. Depression score was relatively low at admission. For the majority of patients, a specific psychological therapy was not indicated. Therefore, no statistically significant reduction in depression score was to be expected, especially after only 3 weeks of rehabilitation. These results are in accordance with data of a former study in patients with coronary heart disease, which also revealed a nonsignificant improvement of depression symptoms during $\mathrm{CR}{ }^{36}$

\section{Limitations}

The description of the patients was focused on variables with functional consequences. Echocardiographic haemodynamic parameters were not reported. Although patients after TAVI were more morbid and older in comparison to sAVR, we did not include the EuroScore or STS score, as the scores are not appropriate for selecting the patients for TAVI. ${ }^{37}$

This study was an observational, nonrandomized study. Since the data for this study were extracted and evaluated retrospectively from a database of our rehabilitation centre, one can assume that it reflects the effect of a usual rehabilitation programme offered.

\section{Conclusions}

The mostly elderly patients after TAVI with multiple comorbidities benefit from CR predominantly in functional performance. Although the improvement at the end of CR was less significant in comparison with younger patients after sAVR, CR is a helpful tool to maintain independency for daily-life activities and participation in socio-cultural life in patients after TAVI. For these patients, prospective multicentre studies including geriatric multidimensional evaluation (e.g. disability, cognitive and nutritional status, and frailty) are required to estimate the improvement of prognosis by $\mathrm{CR}$ more accurately.

\section{Funding}

This research received no specific grant from any funding agency in the public, commercial, or not-for-profit sectors.

\section{Conflict of interest}

The authors declare that there is no conflict of interest.

\section{References}

1. Carabello BA and Paulus WJ. Aortic stenosis. Lancet 2009; 373: 956-966.

2. Schwarz F, Baumann P, Manthey J, et al. The effect of aortic valve replacement on survival. Circulation 1982; 66: 1105-1110.

3. Varadarajan P, Kapoor N, Bansal CR, et al. Clinical profile and natural history of 453 nonsurgically managed patients with severe aortic stenosis. Ann Thorac Surg 2006; 82: 2111-2115.

4. Grube E, Laborde JC, Gerckens U, et al. Percutaneous implantation of the CoreValve self-expanding valve prosthesis in high-risk patients with aortic valve disease: the Siegburg first-in-man study. Circulation 2006; 114: 1616-1624.

5. Leon MB, Smith CR, Mack M, et al. Transcatheter aorticvalve implantation for aortic stenosis in patients who cannot undergo surgery. $N$ Eng $J$ Med 2010; 363: 1597-1607.

6. Makkar RR, Fontana GP, Jilaihawi $H$, et al. Transcatheter aortic valve replacement for inoperable severe aortic stenosis. N Eng J Med 2012; 366: 1696-1704. 
7. Kodali SK, Williams MR, Smith CR, et al. Two-year outcomes after transcatheter or surgical aortic-valve replacement. $N$ Eng J Med 2012; 366: 1686-1695.

8. Smith CR, Leon MB, Mack MJ, et al. Transcatheter versus surgical aortic valve replacement in high risk patients. N Engl J Med 2011; 364: 2187-2198.

9. Holmes DR Jr, Mack MJ, Kaul S, et al. ACCF/AATS/ SCAI/STS expert consensus document on transcatheter aortic valve replacement. J Am Coll Cardiol 2012; 59: 1200-1254.

10. Reynolds MR, Magnuson EA, Lei Y, et al. Healthrelated quality of life after transcatheter aortic valve replacement in inoperable patients with severe aortic stenosis. Circulation 2011; 124: 1964-1972.

11. Bagur R, Rodes-Cabau J, Dumont E, et al. Performancebased functional assessment of patients undergoing transcatheter aortic valve implantation. Am Heart J 2011; 161 : 726-734.

12. Webb JG, Altwegg L, Boone RH, et al. Transcatheter aortic valve implantation. Impact on clinical and valverelated outcomes. Circulation 2009; 119: 3009-3016.

13. Gotzmann M, Hehen T, Germing A, et al. Short-term effects of transcatheter aortic valve implantation on neurohumoral activation, quality of life and 6-minute walk test in severe and symptomatic aortic stenosis. Heart 2010; 96: 1102-1106.

14. Bekeredjian R, Krumsdorf U, Chorianopoulos E, et al. Usefulness of percutaneous aortic valve implantation to improve quality of life in patients $>80$ years of age. Am J Cardiol 2010; 106: 1777-1781.

15. Deutsche Herzstiftung e.V. (ed.) Deutscher Herzbericht 2011. Frankfurt am Main: Deutsche Herzstiftung e.V., 2012.

16. Butchart EG, Gohlke-Bärwolf C, Antunes MJ, et al. Recommendations for the management of patients after heart surgery. Eur Heart $J$ 2005; 26: 2463-2471.

17. Horstkotte D, Lengyel M, Mistiaen WP, et al. Recommendations for post-discharge patient follow up after cardiac valve interventions: a position paper. $J$ Heart Valve 2007; 16: 575-589.

18. Karoff M, Held K, Bjarnason-Wehrens B, et al. Cardiac rehabilitation in Germany. Eur J Cardiovasc Prev Rehabil 2007; 14: 18-27.

19. Alter DA, Oh PI and Chong A. Relationship between cardiac rehabilitation and survival after acute cardiac hospitalization within a universal health care system. Eur J Cardiovasc Prev Rehabil 2009; 16: 102-113.

20. Kiel MK. Cardiac rehabilitation after heart valve surgery. $P M R$ 2011; 3: 962-967.

21. Hermann $C$. International experiences with the hospital anxiety and depression scale: a review of validation data and clinical results. J Psychosom Res 1997; 42: 17-41.

22. Zigmond AS and Snaith RP. The Hospital Anxiety and Depression Scale. Acta Psychiatr Scand 1983; 67: 361-370.

23. Russo N, Compostella L, Tarantini G, et al. Cardiac rehabilitation after transcatheter versus surgical prosthetic valve implantation for aortic stenosis in the elderly. Eur J Prev Cardiol 2013; (Epub ahead of print).

24. De Feo S, Tramarin R, Lorusso R, et al. Six-minute walking test after cardiac surgery: instructions for an appropriate use. Eur J Cardiovasc Prev Rehabil 2009; 16: 144-149.

25. Fiorina C, Vizzardi E, Lorusso R, et al. The 6-min walking test early after cardiac surgery. Reference values and the effects of rehabilitation programme. Eur $J$ Cardiothorac Surg 2007; 32: 724-729.

26. De Feo S, Mazza A, Camera F, et al. Distance covered in walking test after cardiac surgery in patients over 70 years of age: outcome indicator for the assessment of quality of care in intensive rehabilitation. Monaldi Arch Chest Dis 2003; 60: 111-117.

27. Enright PL, McBurnie MA, Bittner V, et al. The 6-min walk test: a quick measure of functional status in elderly adults. Chest 2003; 123: 387-398.

28. Solway S, Brooks D, Lacasse Y, et al. A quantitative systematic overview of the measurement properties of functional walk tests used in the cardiorespiratory domain. Chest 2001; 119: 256-270.

29. Green P, Cohen DJ, Généreux P, et al. Relation between six-minute walk test performance and outcomes after transcatheter aortic valve implantation (from the PARTNER trial). Am J Cardiol 2013; 112: 700-706.

30. Harada ND and Chiu V and Stewart AL. Mobilityrelated function in older adults: assessment with a 6minute walk test. Arch Phys Med Rehabil 1999; 80: 837-841.

31. Steffen TM, Hacker TA and Mollinger L. Age- and gender-related test performance in community-dwelling elderly people: Six-Minute Walk Test, Berg Balance Scale, Timed Up \& Go Test, and Gaited Speed. Phys Ther 2002; 82: 128-137.

32. Opasich C, De F, eo S, Pinna GD, et al. Distance walked in the 6-minute test soon after cardiac surgery. Toward an efficient use in the individual patient. Chest 2004; 126 : 1796-1801.

33. Reibis RK, Treszl A, Wegscheider K, et al. Exercise capacity is the most powerful predictor of 2-year mortality in patients with left ventricular systolic dysfunction. Herz 2010; 35: 104-110.

34. Schoenenberger AW, Stortecky S, Neumann S, et al. Predictors of functional decline in elderly patients undergoing transcatheter aortic valve implantation (TAVI). Eur Heart J 2013; 34: 684-692.

35. Bjelland I, Dahl AA, Haug TT, et al. The validity of the Hospital Anxiety and Depression Scale. An updated literature review. J Psychosom Res 2002; 52: 69-77.

36. Egger E, Schmid JP, Schmid RW, et al. Depression and anxiety symptoms affect change in exercise capacity during cardiac rehabilitation. Eur $J$ Cardiovasc Prev Rehabil 2008; 15: 704-708.

37. Van Mieghem NM and Serruys PW. The art of risk stratification in TAVI. Eur Heart J 2013; 34: 1859-1861. 